\title{
Modification of Type B Inclusions by Calcium Treatment in High-Carbon Hard-Wire Steel
}

\author{
Linzhu Wang ${ }^{1,2}$, Zuobing $\mathrm{Xi}^{1,2}$ and Changrong $\mathrm{Li}^{1,2, *}$ \\ 1 College of Material and Metallurgy, Guizhou University, Guiyang 550025, China; lzwang@gzu.edu.cn (L.W.); \\ bingzxi@163.com (Z.X.) \\ 2 Key Laboratory of Metallurgical Engineering and Process Energy Saving of Guizhou Province, \\ Guiyang 550025, China \\ * Correspondence: crli@gzu.edu.cn; Tel.: +86-130-7855-0950
}

Citation: Wang, L.; Xi, Z.; Li, C. Modification of Type B Inclusions by Calcium Treatment in High-Carbon Hard-Wire Steel. Metals 2021, 11, 676. https://doi.org/10.3390/met11050676

Academic Editors: Beatriz López Soria and Francesca Borgioli

Received: 19 March 2021

Accepted: 13 April 2021

Published: 21 April 2021

Publisher's Note: MDPI stays neutral with regard to jurisdictional claims in published maps and institutional affiliations.

Copyright: (c) 2021 by the authors. Licensee MDPI, Basel, Switzerland. This article is an open access article distributed under the terms and conditions of the Creative Commons Attribution (CC BY) license (https:/ / creativecommons.org/licenses/by/ $4.0 /)$.

\begin{abstract}
To investigate the modification of type B inclusions in high-carbon hard-wire steel with Ca treatment, Si-Ca alloy was added to high-carbon hard-steel, and the composition, morphology, size, quantity, and distribution of inclusions were observed. The samples were investigated by scanning electron microscopy-energy dispersive spectroscopy (SEM-EDS). The experimental thermal results showed that the modification effect of inclusion was better in high-carbon hard-wire steel with $\mathrm{Al}$ of $0.0053 \%$ and $\mathrm{Ca}$ of $0.0029 \%$ than that in steel with $\mathrm{Al}$ of $0.011 \%$ and $\mathrm{Ca}$ of $0.0052 \%$, in which the inclusions were mainly spherical semi-liquid and liquid $\mathrm{CA}_{2}, \mathrm{CA}$, and $\mathrm{C}_{12} \mathrm{~A}_{7}$. The inclusion size decreased from $3.2 \mu \mathrm{m}$ to $2.1 \mu \mathrm{m}$. The degree of inclusions segregation was reduced in high-carbon hard-wire steels after calcium treatment. The results indicate that the modification of inclusions is conducive to obtaining dispersed inclusions with fine size. The ratio of length to width decreased and tended to be 1 with the increase in $\mathrm{CaO}$ content in the inclusion. When the content of $\mathrm{CaO}$ was higher than $30 \%$, the aspect ratio was in the range of 1 to 1.2. The relationship between the activity of aluminum and calcium and the inclusions type at equilibrium in high-carbon hard-wire steel was estimated using classical thermodynamics. The calculated results were consistent with the experimental results. The thermodynamic software Factsage was used to analyze the effect of aluminum and calcium additions on the type and quality of inclusions in high-carbon hard-wire steels. The modification law and mechanism of type B inclusions in high-carbon hard-wire steels are discussed.
\end{abstract}

Keywords: calcium treatment; high-carbon hard-wire steel; $\mathrm{Al}_{2} \mathrm{O}_{3}$ inclusions; thermodynamic calculation

\section{Introduction}

The wire rod rolled by structural steel with carbon content not less than $0.6 \%$ is called high-carbon hard-wire steel, which is widely used in construction, transportation, and other industries [1-3]. Nonmetallic inclusions affect the mechanical properties and corrosion performance of steel [4]. Compared with low-carbon steel, high-carbon steel has high hardness and low ductility and is more sensitive to nonmetallic inclusions $[5,6]$. In recent years, the output and quality of high-carbon hard-wire steel produced in China have been greatly improved. However, the breaking rate of the wire is relatively high during the drawing and twisting processes [7]. Controlling the number, size, distribution, and morphology of brittle inclusions is very important in the smelting process of high-carbon hard-wire steel [1].

B-type inclusions $\left(\mathrm{Al}_{2} \mathrm{O}_{3}\right.$ inclusions) are brittle inclusions and tend to accumulate at the nozzle, which affects the stable operation of the production process [8]. The modification of inclusions is a good way to reduce the adverse effect of B-type inclusions on the production and performance of steel [9-11]. Calcium treatment [12-17] can effectively modify $\mathrm{Al}_{2} \mathrm{O}_{3}$ inclusions into calcium aluminate inclusions with a low melting 
point, which can effectively prevent nozzle clogging [18-21]. Calcium alloy was added into liquid steel by powder spraying or wire feeding to promote the transformation of high melting point $\mathrm{Al}_{2} \mathrm{O}_{3}$ inclusions into plastic or semi-plastic low melting point calcium aluminate inclusions $[22,23]$. The inclusion after calcium treatment is composed of a certain proportion of liquid phase and solid phase, and the composition of the inclusion has a very important effect on the castability and deformation of the inclusion during rolling. Therefore, it is very important to study the phase composition of inclusions during calcium treatment. [24]

Numata et al. [25] studied the effect of calcium content on the modification of inclusions by laboratory experiments. Verma et al. [26] demonstrated that the inclusion size decreased significantly after Ca treatment, mainly from $10-20 \mu \mathrm{m}$ to $1-2.5 \mu \mathrm{m}$. The inclusion size was the smallest after $2 \mathrm{~min}$ of Ca treatment and then gradually increased. Yuan et al. [27] treated medium and high carbon with $\mathrm{Al}$ content of $0.025-0.044 \%$ with calcium. When the Ca content was less than $10 \mathrm{ppm}$, the solid rate of inclusion reached more than $60 \%$, and they believed that the suitable Ca content was 17-23 ppm. Yoshihiko et al. [28] modified the inclusions in mild steel by adding Ca-Si alloy. They found that the modification effect was better in the steel with a Ca content of $20 \mathrm{ppm}$, in which the content of $\mathrm{CaO}$ in the oxide inclusion was close to $50 \%$. Simpson et al. [29] showed that calcium aluminate inclusions with lower melting points formed when the mass ratio of $w[\mathrm{Ca}] / w[\mathrm{Al}]$ is larger than 0.11 in molten steel.

Many studies have been carried out on the treatment of $\mathrm{Al}_{2} \mathrm{O}_{3}$ inclusions with calcium, but most of them were focused on low carbon steel. Limited research was conducted on the modification of B-type inclusions in steel with high carbon. In order to expand the application of calcium in the production of high-carbon hard-wire steel, the effect of calcium treatment on the quantity, morphology, distribution, and composition of B-type inclusions in the molten steel by adding alloy was studied.

\section{Experimental Method}

A vacuum induction furnace was applied in the production of base metal of highcarbon hard-wire steel. Table 1 lists the compositions of raw materials used in the study. The base metal was put into a tubular resistance furnace and heated to $1600{ }^{\circ} \mathrm{C}$. After melting for $30 \mathrm{~min}$, aluminum powder was added, and timing started. The time of adding aluminum powder was recorded as $0 \mathrm{~min}$. After $5 \mathrm{~min}$, calcium alloy was added. After $65 \mathrm{~min}$, the sample was taken out and placed in water for cooling. During the whole smelting process, high purity argon gas was fed into the tubular resistance furnace. The samples can be divided into three groups according to the amount of aluminum alloy and calcium alloy added to the steel. The composition of the three groups of samples is shown in Table 2. In sample 1, only aluminum alloy was added for deoxygenation, and calcium alloy was not added. A large amount of aluminum and calcium was added in sample 2, and a small amount of aluminum and calcium was added in sample 3.

Table 1. Compositions of raw materials (mass \%).

\begin{tabular}{ccccccccc}
\hline Raw Material & Fe & Si & Mn & S & C & Ca & Al & Others \\
\hline Industrial pure iron & 99.7 & 0.02 & 0.03 & 0.0002 & 0.0018 & - & 0.001 & 0.0024 \\
electrolytic manganese & - & - & 99.999 & - & - & - & - & 0.001 \\
Si-Fe alloy & 21 & 78 & 0.4 & 0.02 & 0.1 & - & - & 0.48 \\
Al alloy & 0.7 & 0.8 & 0.15 & - & - & - & 96.94 & 1.41 \\
Si-Ca alloy & - & 57.13 & 20.44 & - & 0.83 & 19.56 & 2.02 & 0.02 \\
QT400 & 95.8 & 0.17 & 0.5 & 0.01 & 3.45 & - & - & 0.07 \\
\hline
\end{tabular}


Table 2. Chemical Composition (Mass Percent).

\begin{tabular}{cccccccccc}
\hline No & $\mathbf{C}$ & $\mathbf{S i}$ & $\mathbf{M n}$ & $\mathbf{S}$ & $\mathbf{A l}$ & $\mathbf{C a}$ & $\mathbf{O}$ & $\mathbf{N}$ & $\mathbf{F e}$ \\
\hline Sample1 & 0.640 & 0.189 & 0.313 & 0.0010 & 0.013 & - & 0.0082 & 0.0024 & Others \\
Sample2 & 0.636 & 0.202 & 0.311 & 0.0012 & 0.011 & 0.0052 & 0.0065 & 0.0029 & Others \\
Sample3 & 0.638 & 0.196 & 0.320 & 0.0011 & 0.0053 & 0.0029 & 0.0053 & 0.0027 & Others \\
\hline
\end{tabular}

The three groups of samples were processed into metallographic samples of $10 \mathrm{~mm}$ $\times 10 \mathrm{~mm} \times 10 \mathrm{~mm}$, rod samples of $\Phi 5 \times 100 \mathrm{~mm}$, and metal chips, respectively. The metallographic samples were ground to a mirror finish with different mesh sandpaper and emery polishing paste. The composition and characteristics of inclusions were analyzed by scanning electron microscope and energy dispersive spectrometer (SEM-EDS). Twenty inclusions were randomly selected from each sample to detect the content of corresponding chemical elements. The composition and type of inclusions were analyzed according to the stoichiometric relationship. One hundred fields of view were selected for each sample. Sample surface pictures were taken under the scanning electron microscope (SEM) 1000× field. Image-ProPlus image processing software was used to analyze the size, quantity, coordinate parameters, and other characteristic values of inclusions.

\section{Experimental Results}

\subsection{Composition and Morphology of Inclusions}

Inclusions with a low deformation rate induce cracks in high-carbon hard-wire steel during drawing, mainly due to the different thermal expansion coefficients between inclusions and steel matrix where a radial tensile force is generated in the matrix around inclusions, which leads to a stress concentration around inclusions. When inclusions change to a spherical shape, the stress concentration around inclusions weakens, which improves the drawing performance of high-carbon hard-wire steel [22].

The composition and morphology of inclusions in three groups of samples are shown in Figure 1. Figure 1a-c shows the composition and morphology of typical inclusions in sample 1 without calcium treatment. It can be seen that all inclusions were alumina inclusions with irregular morphology. Figure $1 \mathrm{~d}-\mathrm{f}$ shows the composition and morphology of typical inclusions in the calcium-treated sample 2. Almost all inclusions in sample 2 were transformed into calcium-aluminate inclusions after $60 \mathrm{~min}$ of calcium treatment, but the morphology of inclusions was still irregular. The inclusions in sample 3 treated with calcium were mainly calcium aluminate, and the content of $\mathrm{CaO}$ in the inclusions was higher than that in sample 2, and the morphology of the inclusions was almost spherical. The surface scanning results of inclusions in Figure 2 also showed that the inclusions in samples 2 and 3 were calcium aluminate, and the elements of $\mathrm{Ca}$ and $\mathrm{Al}$ distributed in inclusions homogeneously.

Figure 3 shows the inclusion composition distribution of samples 2 and 3 . It can be seen that $\mathrm{CaO}$ content in the inclusion of sample 2 was in the range of 5 to $25 \%$, and most of the calcium aluminates were $\mathrm{CA}_{2}$ and $\mathrm{CA}_{6}$. The $\mathrm{CaO}$ content in sample 3 inclusions ranged from 20 to $50 \%$, and most of the calcium aluminates were $\mathrm{CA}_{2}$ and $\mathrm{CA}$. A small amount of $\mathrm{C}_{12} \mathrm{~A}_{7}$ was found in sample 3. According to the phase diagram of $\mathrm{CaO}-\mathrm{Al}_{2} \mathrm{O}_{3}$ calculated by Factsage as shown in Figure 4, the melting point of $\mathrm{CaO}-6 \mathrm{Al}_{2} \mathrm{O}_{3}\left(\mathrm{CA}_{6}\right)$ was $183{ }^{\circ} \mathrm{C}, \mathrm{CaO}-2 \mathrm{Al}_{2} \mathrm{O}_{3}\left(\mathrm{CA}_{2}\right)$ was $1765^{\circ} \mathrm{C}, \mathrm{CaO}-\mathrm{Al}_{2} \mathrm{O}_{3}(\mathrm{CA})$ was $1604^{\circ} \mathrm{C}, 12 \mathrm{CaO}-7 \mathrm{Al}_{2} \mathrm{O}_{3}$ $\left(\mathrm{C}_{12} \mathrm{~A}_{7}\right)$ was $1455^{\circ} \mathrm{C}, 3 \mathrm{CaO}-\mathrm{Al}_{2} \mathrm{O}_{3}\left(\mathrm{C}_{3} \mathrm{~A}\right)$ melting point was $1539^{\circ} \mathrm{C}$. The liquid calcium aluminate at $1600{ }^{\circ} \mathrm{C}$ is marked by shadow area in Figure 3, where the $\mathrm{CaO}$ content was in the range of 37 to $57 \%$. When the composition of calcium aluminate inclusions was between $\mathrm{CA}$ and $\mathrm{CA}_{2}$, the inclusions were semi-liquid at $1600^{\circ} \mathrm{C}$. The calcium aluminate inclusions ranging from $\mathrm{CA}_{2}$ to $\mathrm{CA}_{6}$ were solid-state at $1600{ }^{\circ} \mathrm{C}$. Figure 3 indicates that most of the inclusions in sample 2 were solid and those in sample 3 were semi-liquid or liquid. The inclusion in sample 1 was a solid alumina inclusion. The research $[9,30,31]$ showed that the deformability of inclusion is directly related to its melting point, and the 
lower the melting point, the better the deformability. The modification of B-type brittle inclusions into low melting point plastic inclusions will reduce their harmful effects on the production and performance of steel. At the same time, it also showed that the inclusion in sample 3 had a good deformation effect.

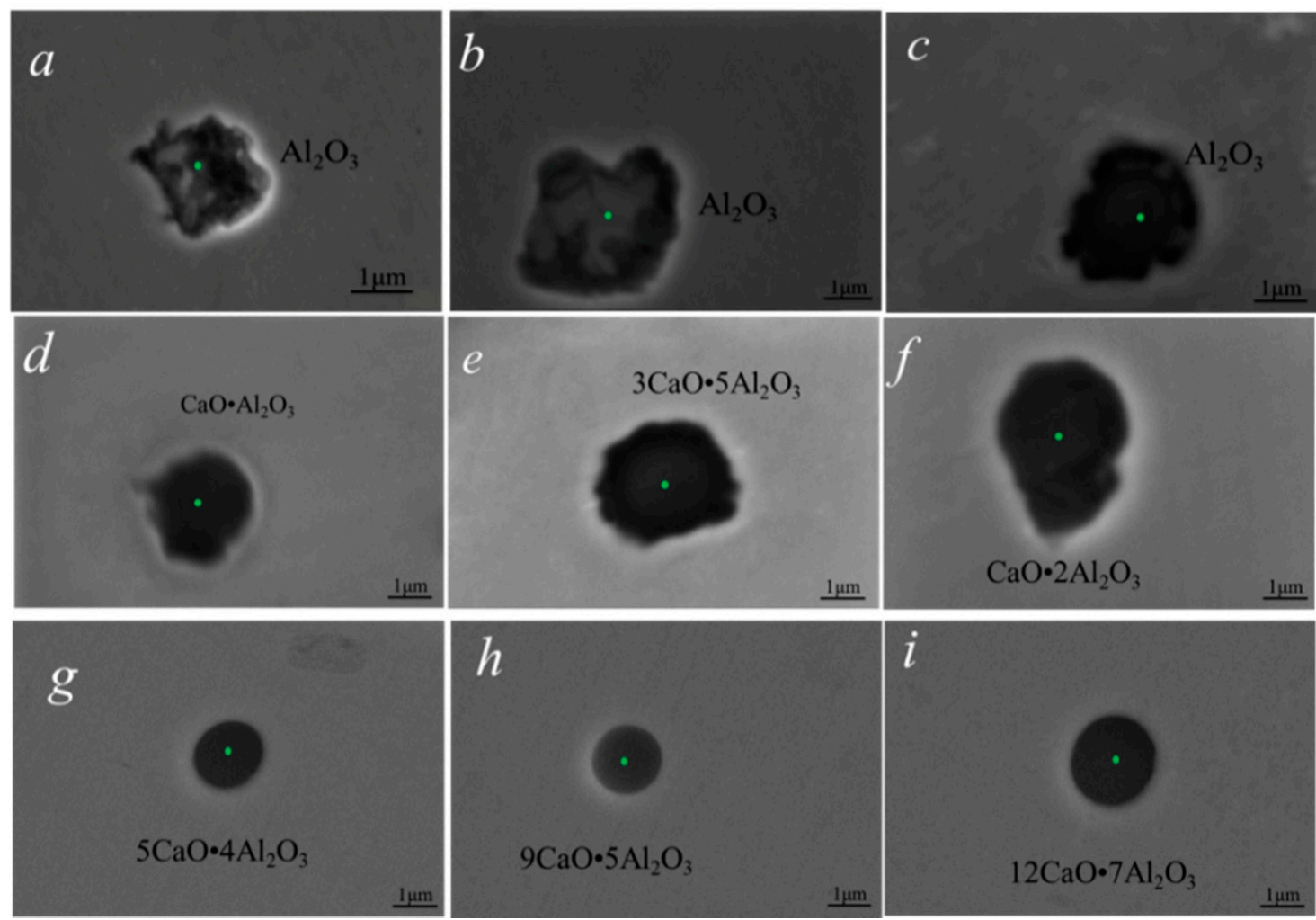

Figure 1. Morphologies of typical inclusions in high-carbon hard-wire steels. (a-c) are inclusions in sample $1 ;(\mathbf{d}-\mathbf{f})$ are inclusions in sample 2; (g-i) are inclusions in sample 3.
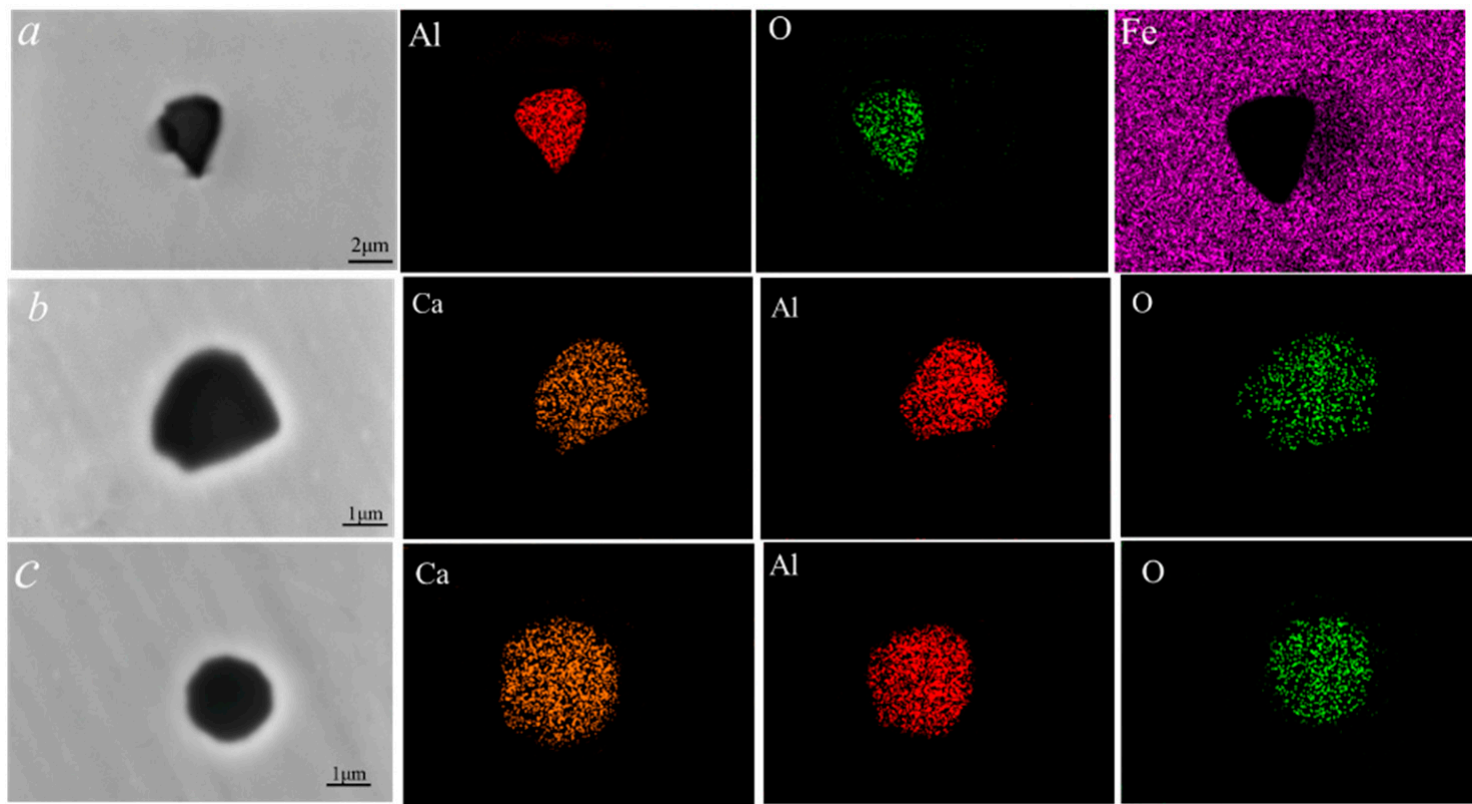

Figure 2. Elemental mapping of typical inclusion in high-carbon hard-wire steels. (a) are inclusions without Ca treatment in sample $1 ;(\mathbf{b})$ are inclusions after modification when calcium content is $0.0052 \%$ in sample 2 ; (c) are inclusions after modification when calcium content was $0.0029 \%$ in sample 3. 


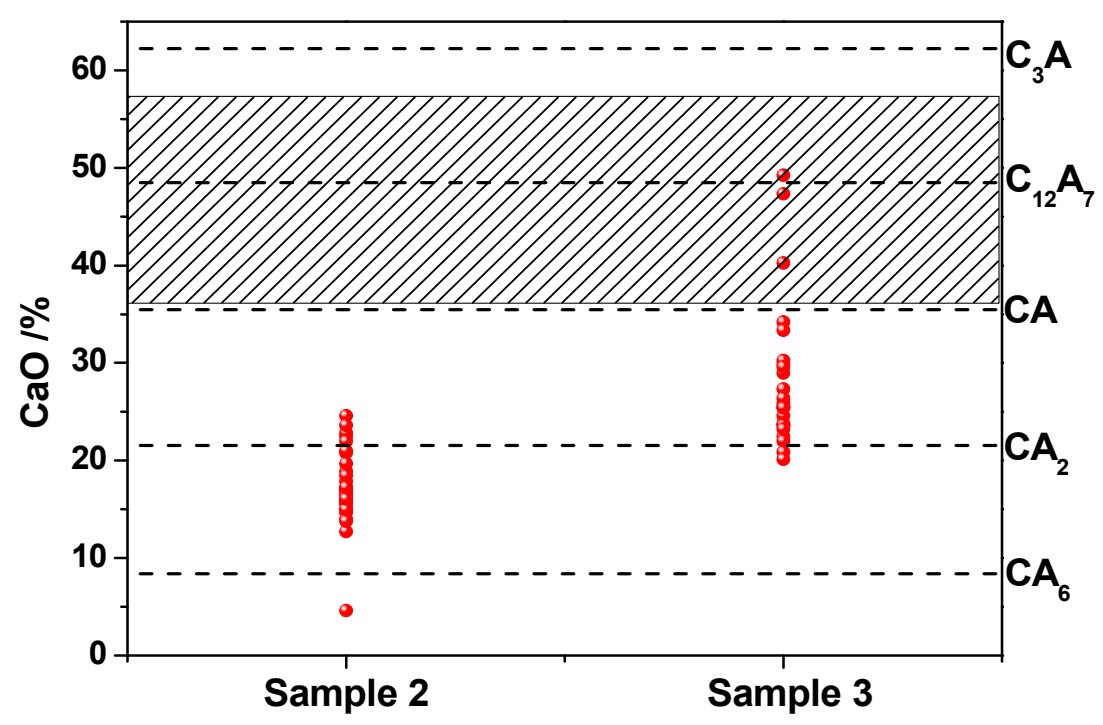

Figure 3. Composition distribution of inclusion in high-carbon hard-wire steels.

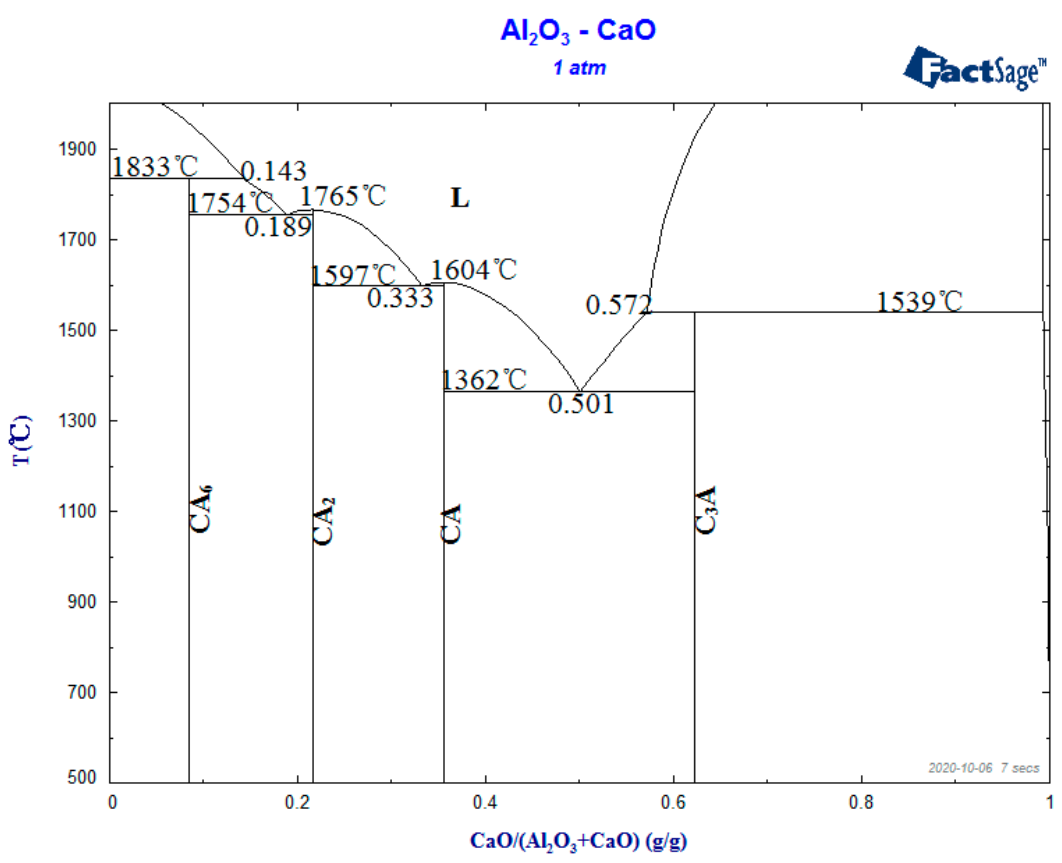

Figure 4. $\mathrm{CaO}-\mathrm{Al}_{2} \mathrm{O}_{3}$ system phase diagrams.

In order to explore the relationship between inclusion morphology and inclusion composition, the relationship between $\mathrm{CaO}$ content in inclusion and inclusion aspect ratio was statistically analyzed in this study, as shown in Figure 5. With the increase in calcium oxide content in the calcium aluminate inclusions, the ratio of length to width was closer to 1 . When the content of $\mathrm{CaO}$ was higher than $30 \%$, the aspect ratio was in the range of 1 to 1.2 , indicating that the inclusion was approximately spherical. The main reason is that when the content of calcium oxide in the calcium aluminate inclusions was higher than $30 \%$, the inclusions were located in the solid-liquid two-phase region or the liquid phase region. 


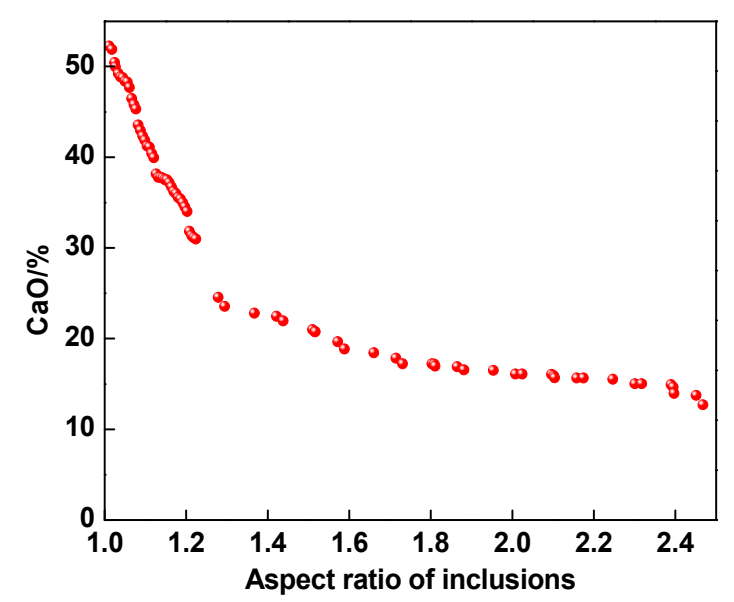

Figure 5. Relationship between aspect ratio and composition of inclusions in high-carbon hardwire steels.

\subsection{Size and Number of Inclusions}

Figure 6 shows the inclusion size distribution in high-carbon hard-wire steels. Among the three groups of samples, the inclusion size of sample 1 was the most widely distributed, and the diameter of the largest inclusion was more than $10 \mu \mathrm{m}$. The size of the largest inclusion was less than $8 \mu \mathrm{m}$ in the samples treated with calcium, i.e., samples 2 and 3 . The number of inclusions with 1-3 $\mu \mathrm{m}$ was the largest in these three groups of samples.
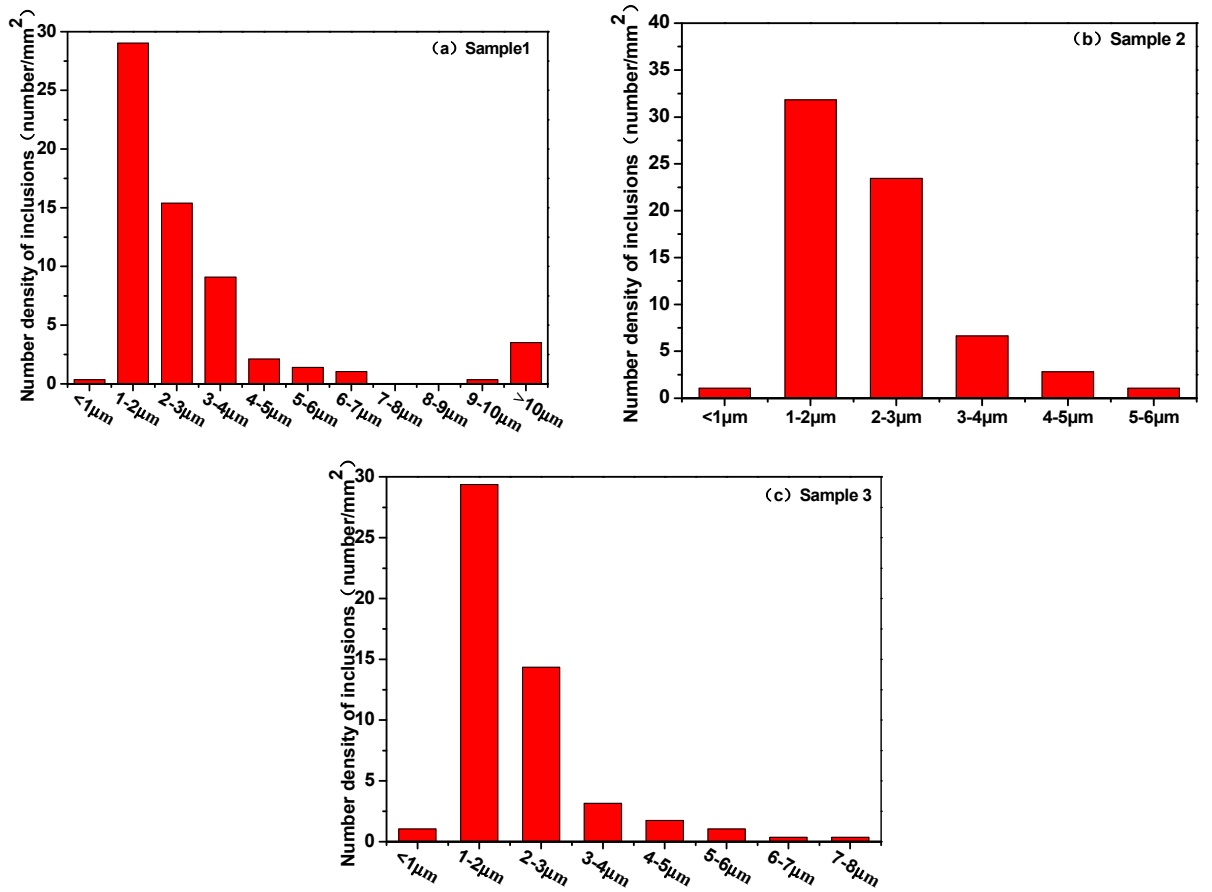

Figure 6. Size distribution of inclusion in high—carbon hard-wire steels. (a)Sample 1; (b) Sample 2; (c) Sample 3.

According to the analysis of the average size and number of inclusions in Figure 7, it can be seen that the average size of inclusions in calcium-treated steel was significantly smaller than that of high-carbon hard-wire steel without calcium treatment. The size of inclusion in sample 3 was obviously smaller than that in sample 2, indicating that the better modification of inclusion is beneficial to the refinement of inclusions. In addition, the number of inclusions in sample 2 was the largest, while the number of inclusions in sample 3 was the least. 


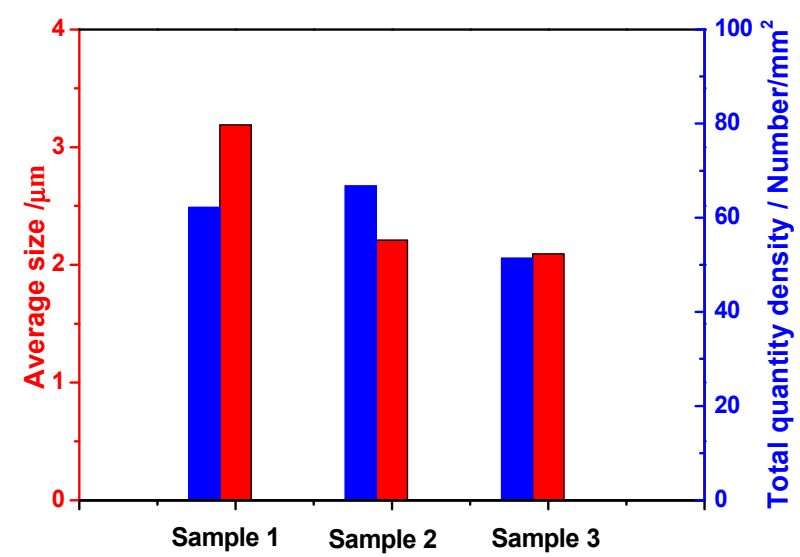

Figure 7. Average size and total quantity density of inclusions in high-carbon hard-wire steels.

\subsection{Surface Density Distribution of Inclusions}

To describe the distribution of inclusions directly, the area percentage of inclusions at different locations on the surface of the steel sample was statistically obtained according to the two-dimensional coordinates of the inclusions and the area of each inclusion, as shown in Figure 8. Area density represents the percentage of inclusion area to sample area, and it was obtained by Equation (1).

$$
A=\frac{A_{\text {inclusion }}}{A_{\text {steel }}} \times 100 \%
$$

where $A$ represents the area density of inclusions on the surface of the steel sample. Ainclusion represents the total area of all inclusions in the observed region. Asteel is the area of steel in the observed region, and it was $0.0286 \mathrm{~mm}^{2}$ in this study.
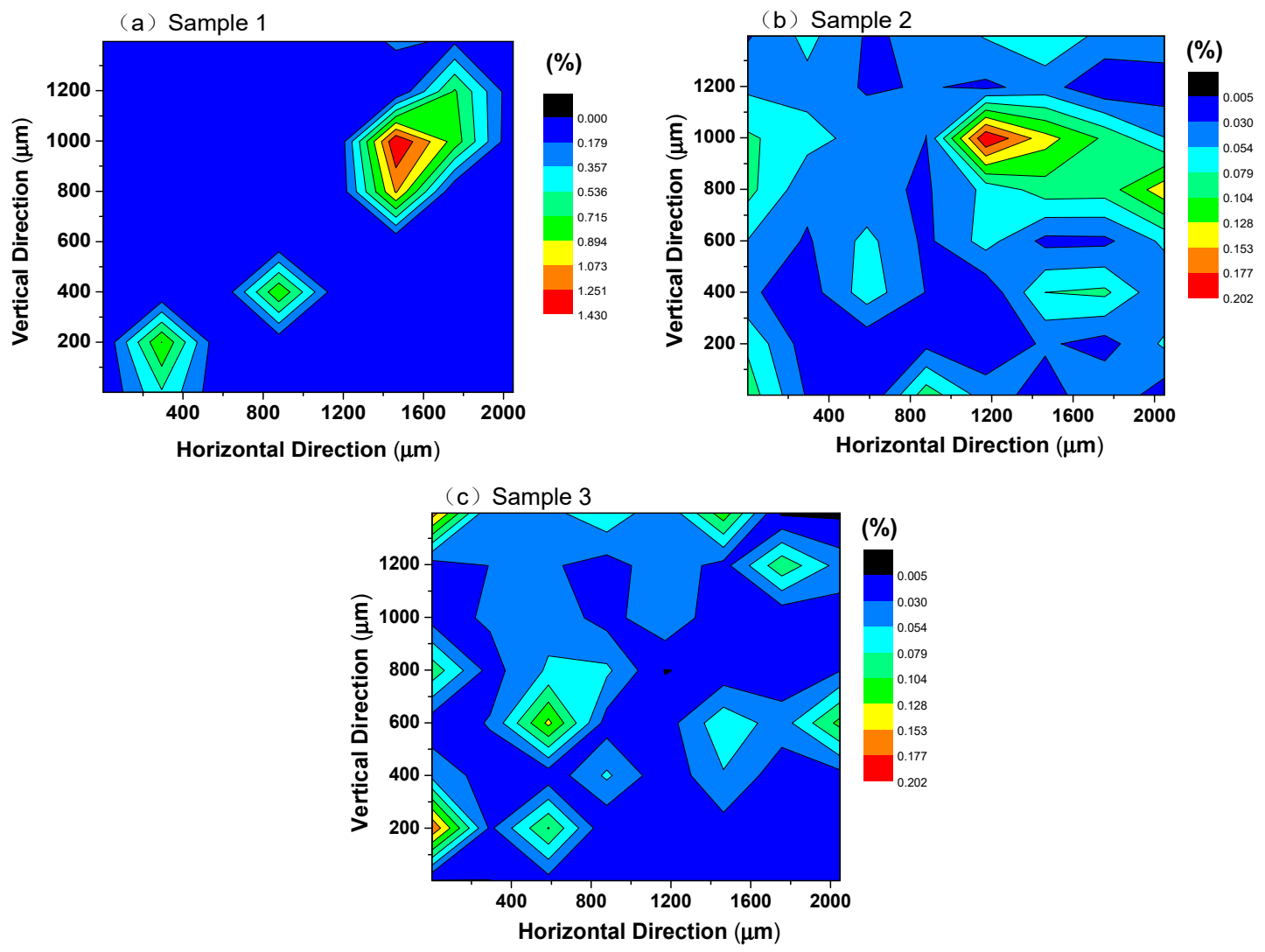

Figure 8. Area density distribution of inclusions in high-carbon hard-wire steels. (a)Sample 1; (b) Sample 2; (c) Sample 3. 
It can be observed that the distribution of inclusions was not uniform in the highcarbon hard-wire steel without calcium treatment. The density of inclusions per unit area on the steel surface was high in sample 1. The inclusions aggregate in the red region in Figure $8 \mathrm{a}$ and the maximum density of inclusions reached $1.4 \%$ in sample 1 . The density of inclusions in calcium-treated steels was less than $0.2 \%$, and the distribution of calcium-aluminate inclusions was more uniform than that of alumina inclusions. In addition, the segregation area of inclusion in sample 3 was smaller than that in sample 2, indicating that the inclusions tend to distribute more homogeneously in steel with a better modification effect.

In conclusion, the inclusions were modified after calcium treatment of high-carbon hard-wire steel. The modification of inclusions in sample 3 was better, where the $\mathrm{CaO}$ content of inclusions was higher, and there were more liquid and semi-liquid inclusions. Furthermore, the dispersed inclusions with fine size were obtained in sample 3 because the liquid calcium aluminate inclusions have good wettability.

\section{Discussion}

According to the detected results of inclusion composition, it is concluded that the chemical reactions that occur in the formation process of a calcium aluminate inclusion in hard-wire steel are (2)-(7) [32,33]

$$
\begin{gathered}
2[\mathrm{Al}]+3[\mathrm{O}]=\mathrm{Al}_{2} \mathrm{O}_{3} ; \Delta \mathrm{G}_{1}^{\theta}=-1,202,000+386.3 \mathrm{~T}, \mathrm{~J} \cdot \mathrm{mol}^{-1} \\
3[\mathrm{Ca}]+19 \mathrm{Al}_{2} \mathrm{O}_{3}=3\left(\mathrm{CaO} \cdot 6 \mathrm{Al}_{2} \mathrm{O}_{3}\right)+2[\mathrm{Al}] ; \Delta \mathrm{G}_{2}^{\theta}=-786,553-59.9 \mathrm{~T}, \mathrm{~J} \cdot \mathrm{mol}^{-1} \\
12[\mathrm{Ca}]+7\left(\mathrm{CaO} \cdot 6 \mathrm{Al}_{2} \mathrm{O}_{3}\right)=19\left(\mathrm{CaO} \cdot 2 \mathrm{Al}_{2} \mathrm{O}_{3}\right)+8[\mathrm{Al}] ; \Delta \mathrm{G}_{3}^{\theta}=-3,134,242-19.58 \mathrm{~T}, \mathrm{~J} \cdot \mathrm{mol}^{-1} \\
3[\mathrm{Ca}]+4\left(\mathrm{CaO} \cdot 2 \mathrm{Al}_{2} \mathrm{O}_{3}\right)=7\left(\mathrm{CaO} \cdot \mathrm{Al}_{2} \mathrm{O}_{3}\right)+2[\mathrm{Al}] ; \Delta \mathrm{G}_{4}^{\theta}=-802,303+30.7, \mathrm{~J} \cdot \mathrm{mol}^{-1} \\
15[\mathrm{Ca}]+33\left(\mathrm{CaO} \cdot \mathrm{Al}_{2} \mathrm{O}_{3}\right)=4\left(12 \mathrm{CaO} \cdot 7 \mathrm{Al}_{2} \mathrm{O}_{3}\right)+10[\mathrm{Al}] ; \Delta \mathrm{G}_{5}^{\theta}=-3,134,242-19.58 \mathrm{~T}, \mathrm{~J} \cdot \mathrm{mol}^{-1} \\
9[\mathrm{Ca}]+2\left(12 \mathrm{CaO} \cdot 7 \mathrm{Al}_{2} \mathrm{O}_{3}\right)=11\left(3 \mathrm{CaO} \cdot \mathrm{Al}_{2} \mathrm{O}_{3}\right)+14[\mathrm{Al}] ; \Delta \mathrm{G}_{6}^{\theta}=-2,868,511+1108.65 \mathrm{~T}, \mathrm{~J} \cdot \mathrm{mol}^{-1}
\end{gathered}
$$

The activity of solute in molten steel can be calculated according to Equation (8)

$$
a_{i}=f_{i}[\% i]
$$

$a_{i}, f_{i}$ and [\%i] are the activity, activity coefficient, and mass fraction of solute $i$ in steel, respectively. The activity coefficient of solute in molten steel was calculated by the Wagner model [34,35]:

$$
\lg f_{i}=\sum\left(e_{i}^{j} \cdot[\% j]+\gamma_{i}^{j} \cdot[\% j]^{2}\right)
$$

where $i$ and $j$ represent different solutes, $e_{i}^{j}$ is the first-order interaction coefficients, and $\gamma_{i}^{j}$ is second-order interaction coefficient. Table 3 [36] and Table 4 [37] list the value of $e_{i}^{j}$ and $\gamma_{i}^{j}$, respectively.

Table 3. First-order interaction coefficients of elements with $\mathrm{Al}$ and Ca in molten steel (1873 K).

\begin{tabular}{cccccccc}
\hline $\boldsymbol{e}_{\boldsymbol{i}}^{j}$ & $\mathbf{C}$ & $\mathbf{S i}$ & $\mathbf{M n}$ & $\mathbf{S}$ & $\mathbf{A l}$ & $\mathbf{O}$ & $\mathbf{C a}$ \\
\hline $\mathrm{Ca}$ & -0.34 & -0.095 & -0.007 & -28 & -0.072 & -780 & -0.002 \\
$\mathrm{Al}$ & 0.091 & 0.056 & -0.004 & 0.035 & -0.043 & -1.98 & -0.047 \\
\hline
\end{tabular}

Table 4. Second-order interaction coefficients of elements with Al and Ca in molten steel (1873 K).

\begin{tabular}{cccc}
\hline$\gamma_{i}^{j}$ & Ca & Al & O \\
\hline $\mathrm{Ca}$ & - & - & $-36,000$ \\
$\mathrm{Al}$ & - & -0.0284 & - \\
\hline
\end{tabular}


Combined with the data in Tables 2-4, Formulas (7) and (8) were used to calculate the activity coefficient and activity of $\mathrm{Ca}$ and $\mathrm{Al}$ in sample 2 and sample 3 and listed in Table 5 .

Table 5. Activity coefficient and activity of $\mathrm{Ca}$ and $\mathrm{Al}$ in test steel.

\begin{tabular}{ccccc}
\hline No. & $f_{\mathrm{Al}}$ & $a_{\mathrm{Al}}$ & $f_{\mathrm{Ca}}$ & $a_{\mathrm{Ca}}$ \\
\hline 2 & 1.138 & 0.0125 & $1.37 \times 10^{-7}$ & $7.13 \times 10^{-10}$ \\
3 & 1.143 & 0.006 & $3.85 \times 10^{-6}$ & $1.08 \times 10^{-8}$ \\
\hline
\end{tabular}

According to the thermodynamic data of chemical reactions (3)-(7) in molten steel, the classical thermodynamic calculated method was adopted to obtain the equilibrium relations of various calcium aluminate salts, as shown in Figure 9. According to Figure 9, when $a_{\mathrm{Al}}$ was more than 0.0030 , the type of calcium-aluminate inclusions mainly depended on the calcium activity in steel. With the increase in calcium activity, the inclusions gradually underwent the following transformation: $\mathrm{Al}_{2} \mathrm{O}_{3} \rightarrow \mathrm{CA}_{6} \rightarrow \mathrm{CA}_{2} \rightarrow \mathrm{CA} \rightarrow \mathrm{C}_{12} \mathrm{~A}_{7} \rightarrow \mathrm{C}_{3} \mathrm{~A}$. According to the activity of calcium and aluminum in samples 2 and 3 , as shown in Table 5, two points in Figure 8 were obtained. The thermodynamic calculated results showed that the types of inclusions at equilibrium in sample 2 were $\mathrm{CA}_{6}$ and $\mathrm{CA}_{2}$, and the types of inclusions in sample 3 were $C A$ and $C_{12} A_{7}$, which was consistent with the experimental test results.

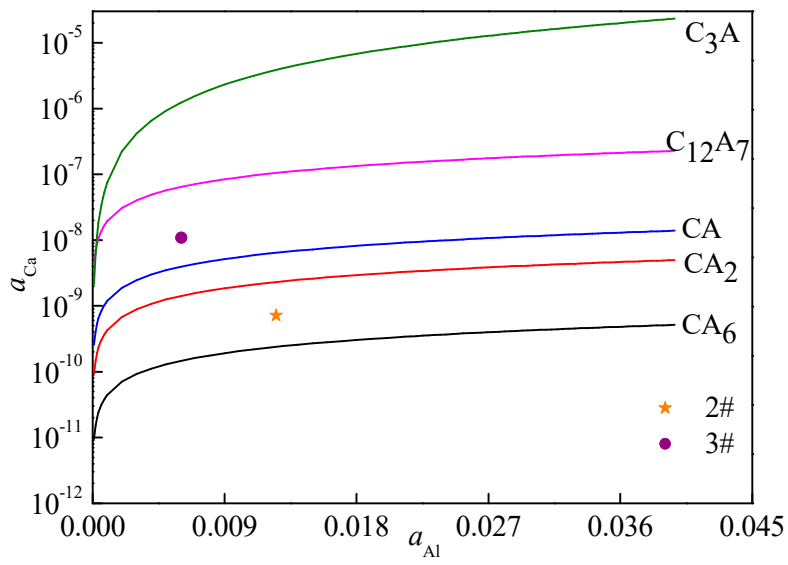

Figure 9. Calculated inclusion stability diagrams in the $a_{\mathrm{Al}}-a_{\mathrm{Ca}}$ equilibrium at $1873 \mathrm{~K}$.

To study the modification of type B inclusion in high-carbon hard-wire steel, Factsage 7.2 software was used and combined with the high-carbon hard-wire steel composition in Table 2. The effect of the amount of $\mathrm{Ca}$ and $\mathrm{Al}$ addition on the composition and quality of inclusions in the high-carbon hard-wire steel was calculated and illustrated in Figure 10. It indicates that the inclusions were alumina, solid calcium aluminate, liquid oxide, and calcium silicate in high-carbon hard-wire steel when adding Ca ranging from 0 to $0.0080 \%$ and adding $\mathrm{Al}$ ranging from $0.0050 \%$ to $0.0150 \%$. When the amount of added aluminum was $0.0050 \%$, the alumina inclusion gradually turned into liquid calcium aluminate with an increase in $\mathrm{Al}$ content. There was a small amount of solid calcium aluminate with the addition of calcium in steel ranging from $0.0020 \%$ to $0.0021 \%$. As the amount of calcium was less than $0.0070 \%$, the amount of liquid oxide increased with the increase in calcium addition. When the amount of calcium addition was greater than $0.0070 \%$, the amount of liquid oxide was reduced with an increase in calcium addition, which was transfer into calcium silicate. As the addition amount of aluminum was $0.01 \%$ and $0.015 \%$, the content of $\mathrm{CaO}$ in liquid calcium aluminate increased with the increase in calcium content, and the inclusions gradually underwent the following transformation: $\mathrm{Al}_{2} \mathrm{O}_{3} \rightarrow \mathrm{CA}_{6} \rightarrow \mathrm{CA}_{2} \rightarrow$ liquid calcium aluminate. The appropriate amount of $\mathrm{Ca}$ addition to modify B-type inclusions into calcium aluminates was less in high-carbon hard-wire steel with lower aluminum content. 

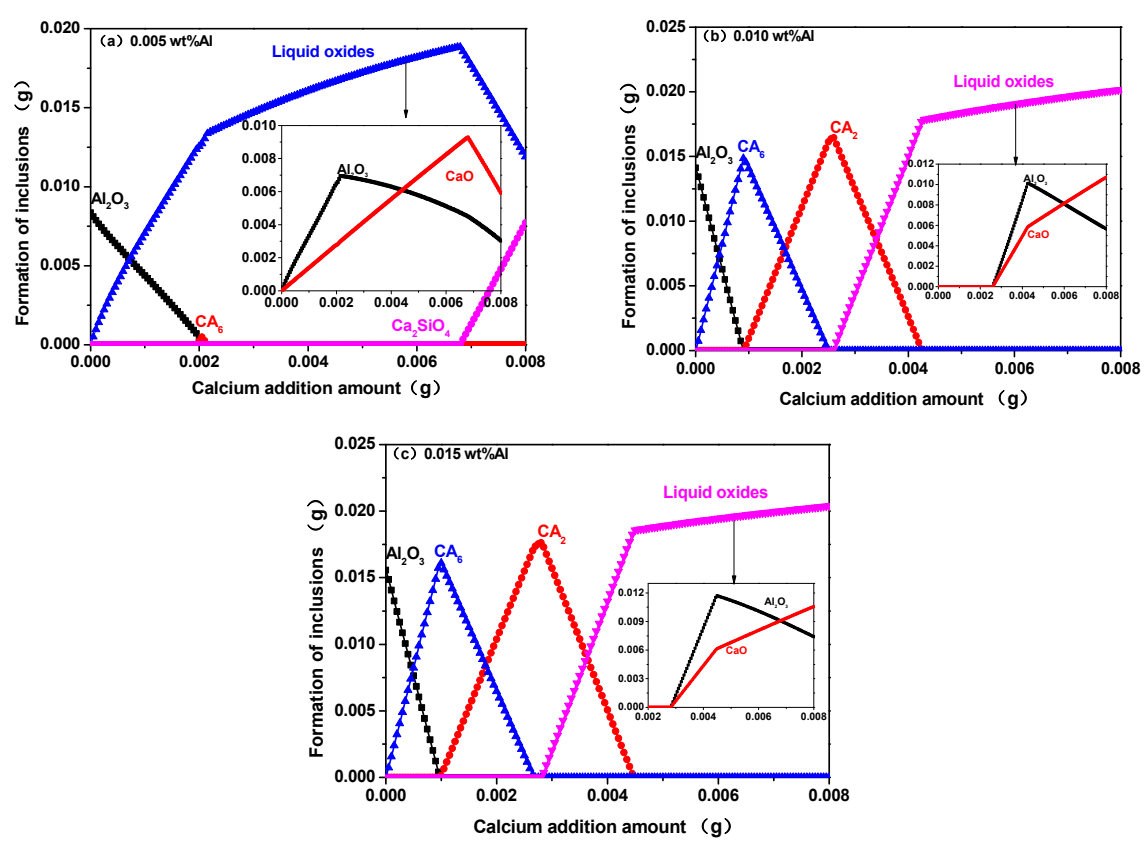

Figure 10. Effect of amount of adding $\mathrm{Al}$ and $\mathrm{Ca}$ content on inclusion composition at $1873 \mathrm{~K}$. (a) $0.005 \mathrm{wt} \% \mathrm{Al}$; (b) $0.010 \mathrm{wt} \% \mathrm{Al}$; (c) $0.015 \mathrm{wt} \% \mathrm{Al}$.

\section{Conclusions}

The mechanism and law on the modification of type B inclusions in high-carbon hardwire steel with $\mathrm{Ca}$ treatment were studied by thermal experiment and thermodynamic calculation. The main conclusions are as follows:

(1) Ca treatment has a great effect on the composition and morphology of type B inclusions in high-carbon hard-wire steels. The modification effect of inclusion was better in high-carbon hard-wire steel with $\mathrm{Al}$ of $0.0053 \%$ and $\mathrm{Ca}$ of $0.0029 \%$ than that in steel with $\mathrm{Al}$ of $0.011 \%$ and $\mathrm{Ca}$ of $0.0052 \%$, in which the inclusions were mainly spherical semi-liquid and liquid $\mathrm{CA}_{2}, \mathrm{CA}$, and $\mathrm{C}_{12} \mathrm{~A}_{7}$. The experimental results have a good agreement with the classical thermodynamic calculation results.

(2) $\mathrm{CaO}$ content in calcium aluminate inclusions directly affects the morphology of inclusions. The ratio of length to width decreases and tend to be 1 with the increase in $\mathrm{CaO}$ content in the inclusion. When the content of $\mathrm{CaO}$ was higher than $30 \%$, the aspect ratio was in the range of 1 to 1.2 , indicating that the inclusion is approximately spherical. The main reason is that when the content of calcium oxide in the calcium aluminate inclusions is higher than $30 \%$, the inclusions are located in the solid-liquid two-phase region or the liquid phase region.

(3) The size distribution of inclusion in high-carbon hard-wire steel became narrower, and inclusion size was smaller, and inclusions were distributed more uniformly in highcarbon hard-wire steels after calcium treatment. It indicates that the modification of inclusions is conducive to obtaining dispersed inclusions with fine size. Compared with the high-carbon hard-wire steel without calcium treatment, when the calcium content was $0.0029 \%$, the average size of inclusion decreased from 3.2 to 2.1 , and the inclusions were difficult to segregate.

(4) The thermodynamic calculated results based on Factsage indicate that when the added amount of aluminum was $0.0050 \%$, the alumina inclusions gradually changed into liquid calcium aluminate inclusions with the increase in the addition amount of calcium in the high-carbon hard-wire steel. When the addition amount of aluminum was $0.01 \%$ and $0.015 \%$, the content of $\mathrm{CaO}$ in liquid calcium aluminate increased with the increase in calcium addition in high-carbon hard-wire steels, and the inclusions gradually underwent the following transformation: $\mathrm{Al}_{2} \mathrm{O}_{3} \rightarrow \mathrm{CA}_{6} \rightarrow \mathrm{CA}_{2} \rightarrow$ liquid calcium aluminate. 
The appropriate amount of $\mathrm{Ca}$ addition to modify B-type inclusions into calcium aluminates is less in high-carbon hard-wire steel with a lower aluminum content.

Author Contributions: Conceptualization, L.W.; methodology, Z.X.; software, L.W. and Z.X.; writingoriginal draft preparation, L.W. and Z.X.; writing-review and editing, L.W. and C.L. All authors have read and agreed to the published version of the manuscript.

Funding: This work was financially supported by the National Science Foundation of China (Grant No 51864013, No 51804086, and No 52074095), and the National Natural Science Foundation of Guizhou Province (Grant No. [2019]1086).

Institutional Review Board Statement: Not applicable.

Informed Consent Statement: Not applicable.

Data Availability Statement: Data is contained within the article.

Conflicts of Interest: The authors declare no conflict of interest.

\section{References}

1. Han, K.; Edmonds, D.V.; Smith, G. Optimization of mechanical properties of high-carbon pearlitic steels with Si and V additions. Met. Mater. Trans. A 2001, 32, 1313-1324. [CrossRef]

2. Elwazri, A.; Wanjara, P.; Yue, S. Measurement of pearlite interlamellar spacing in hypereutectoid steels. Mater. Charact. 2005, 54, 473-478. [CrossRef]

3. Ning, D.; Yan, B.; Jia, Y.; De, Z.; Xiang, K.; Li, W. Study on refining slag and inclusions in 82B hard wire steel. J. Univ. Sci. Technol. B 2012, 34, 883-886.

4. Handoko, W.; Anurag, A.; Pahlevani, F. Effect of selective-precipitations process on the corrosion resistance and hardness of dual-phase high-carbon steel. Sci. Rep. 2019, 9, 15631. [CrossRef]

5. Khoroshailov, V.G.; Zhukova, L.T.; Lashkova, E.G. Nonmetallic inclusions in steel U10A wire. Met. Sci. Heat Treat. 1990, 32, 881-883. [CrossRef]

6. Tanaka, Y.; Pahlevani, F.; Kitamura, S.-Y.; Privat, K.; Sahajwalla, V. Behaviour of Sulphide and Non-alumina-Based Oxide Inclusions in Ca-Treated High-Carbon Steel. Met. Mater. Trans. A 2020, 51, 1384-1394. [CrossRef]

7. Hong, B.; Yao, T. Quality comparison of the high carbon steel for domestic and foreign cord wire application. Met. Heat Treat. 2019, 44, 44-48.

8. Lin, W.; Jun, L.; Shu, Y.; Chao, C.; Hui, J. Effect of calcium treatment on characteristics of non-metallic inclusions in steel containing high Al. Iron Steel 2019, 54, 27-32.

9. Zhang, J.; Wang, F.M.; Li, C.R. Thermodynamic analysis of the compositional control of inclusions in cutting-wire steel. Int. J. Min. Met. Mater. 2014, 21, 647-653. [CrossRef]

10. Suito, H.; Inoue, R. Thermodynamics on control of inclusions composition in ultra-clean steels. ISIJ Int. 1996, 5, 528. [CrossRef]

11. Sunday, A.; Rick, B.; Justin, R.; Yu, W. Inclusion Engineering and the Metallurgy of Calcium Treatment. Iron Steel Technol. 2018, 25, 133-145.

12. Zhen, L.; Wen, Y.; Ying, R.; Li, Z.; Wei, W. Analysis of influencing factors on effect of calcium treatment in Al-killed steels. Iron Steel 2020, 55, 29-34.

13. Wen, Y.; Chao, L.; Li, Z.; Yan, L. Reduction of B type inclusions in pipeline steel by optimizing calcium treatment. Metall. China 2018, 28, 70-75.

14. Li, Z. Several important scientific research points of non-metallic inclusions in steel. Steel Mak. 2016, 32, 1-16.

15. Shu, L.; Ying, R.; Li, Z.; Wen, Y. Study on $\mathrm{CaO}$ and $\mathrm{CaS}$ inclusions in pipeline steel during refining process. J. Univ. Sci. Technol. B 2014, 36, 168-172.

16. Yan, S.; Hui, X.; Xiao, W. Metallurgy effect of calcium treatment in high grade pipeline steel. J. Univ. Sci. Technol. B 2011, 33, 116-120.

17. Xue, Y. Investigation of Non-Metallic Inclusion Plasticization Control for Automotive Suspension Spring Steel. Ph.D. Thesis, University of Science \& Technology Beijing, Beijing, China, 2017.

18. Guang, Y.; Xin, W.; Fu, H. Influence of Calcium Addition on Inclusions in LCAK Steel with Ultralow Sulfur Content. Met. Mater. Trans. B 2014, 46 B, 1-10.

19. Lind, M.; Holappa, L. Transformation of Alumina Inclusions by Calcium Treatment. Met. Mater. Trans. B 2010, 41, 359-366. [CrossRef]

20. Jian, L.; Hua, W.; Yan, B. Inclusion variations and calcium treatment optimization in pipeline steel production. Int. J. Min. Met. Mater. 2011, 18, 527-534.

21. Yang, D.; Wang, X.; Yang, G. Inclusion Evolution and Estimation during Secondary Refining in Calcium Treated Aluminum Killed Steels. Steel Res. Int. 2015, 85, 1517-1524. [CrossRef] 
22. Abraham, S.; Bodnar, R.; Raines, J. Inclusion engineering and metallurgy of calcium treatment. J. Iron Steel Res. Int. 2018, 1, 1243-1257. [CrossRef]

23. Verma, N.; Pistorius, P.C.; Fruehan, R.J. Transient Inclusion Evolution during Modification of Alumina Inclusions by Calcium in Liquid Steel: Part I. Background, Experimental Techniques and Analysis Methods. Met. Mater. Trans. B 2011, 42, 711-719. [CrossRef]

24. Bielefeldt, W.V.; Vilela, A.C. Computational Thermodynamic Study of Inclusions Formation in the Continuous Casting of SAE 8620 Steel. Steel Res. Int. 2010, 81, 1064-1069. [CrossRef]

25. Numata, M.; Higuchi, Y. Change in Inclusion Composition during CaO Flux Powder Blowing under Reduced Pressure. ISIJ Int. 2012, 52, 2013-2018. [CrossRef]

26. Verma, N.; Petrus, C.; Torius, P. Transient inclusion evolution during modification of alumina inclusions by calcium in liquid Steel: Part 2 results and discussion. Met. Mater. Trans. B 2011, 42, 720. [CrossRef]

27. Fang, Y.; Xin, W.; Xue, Y. Influence of calcium content on solid ratio of inclusions in Ca-treated liquid steel. Int. J. Min. Met. Mater. 2011, 8, 18-23.

28. Yoshihiko, H.; Mitsuhiro, N.; Shin, F. Effect of method of Ca treatment on composition and shape of non-matallic inclusions. Tetsu Hagane 1996, 82, 671-676.

29. Simpson, I.D.; Tritsiniotis, Z.; Moore, L.G. Steel cleanness requirements for X65 to X80 electric resistance welded linepipe steels. Ironmak. Steelmak. 2003, 30, 158-164. [CrossRef]

30. Kume, K.; Morita, K.; Miki, T.; Sano, N. Activity measurement of $\mathrm{CaO}-\mathrm{SiO}_{2}-\mathrm{Al}_{2} \mathrm{O}_{3}-\mathrm{MgO}$ slags equilibrated with molten silicon alloys. ISIJ Int. 2000, 6, 561. [CrossRef]

31. Wang, H.T.; Wang, F.M.; Xu, Z.B.; Jin, L.L. Composition control of CaO-MgO- $\mathrm{Al}_{2} \mathrm{O}_{3}-\mathrm{SiO}_{2}$ inclusion in tire cord steel: A thermodynamic analysis. Steel Res. Int 2008, 1, 25. [CrossRef]

32. Choudhary, S.K.; Ghosh, A. Thermodynamic Evaluation of Formation of Oxide-Sulfide Duplex Inclusions in Steel. ISIJ Int. 2008, 48, 1552-1559. [CrossRef]

33. Jun, Y.; Jiang, D.; Bo, C.; Jun, W. Influence of calcium treatment on oxide inclusions in ultra-low oxygen refining process. Iron Steel 2015, 50, 19-26.

34. Paek, M.K.; Jang, J.M.; Jiang, M. Thermodynamics of AlN formation in high manganese aluminum alloyed liquid steels. ISIJ Int. 2013, 53, 973. [CrossRef]

35. Pan, C.; Hu, X.; Zheng, J. Effect of calcium content on inclusions during the ladle furnace refining process of AISI 321 stainless steel. Int. J. Min. Met. Mater. 2020, 27, 1499-1507. [CrossRef]

36. Itoh, H.; Hino, M. Thermodynamics on the formation of spinel nonmetallic inclusion in liquid steel. Met. Mater. Trans. B 1997, 28, 953-956. [CrossRef]

37. Lin, W. Study on the Refinement and Homogenized Distribution of Inclusions in Al Killed Steel. Ph.D. Thesis, University of Science \& Technology Beijing, Beijing, China, 2017. 